\title{
K.P. Ivanov
}

I.P. Pavlov Institute of Physiology. St. Petersburg, Russian Federation

\section{Resuscitation of Vital Activity after Cold Arrest of Respiration by Physiological Methods without Rewarming the Body}

The arrest of respiration during deep hypothermia means death, though at a low temperature the heart may rhythmically contract for 30-40 minutes more. The attempts of rewarming only shorten the time before the heart arrest. "The aim of the study" the attempts to develop the methods of stimulating the respiration and heart without rewarming the body. Calcium ions $\left(\mathrm{Ca}^{2+}\right)$ are believed to accumulate in the nervous cells in cold. An excess of these ions inhibits the metabolism. Moreover it stimulates the cell proteases, which destroy the cell membranes. "Materials and methods" The work was carried out on wite rats 250-320 g in weight. We introduced disodium salt of ethylenediaminetetraacetic acid (EDTA) into the animals. The second method of blocking the mechanisms of the cold death was artificial respiration. "Results"EDTA reacts with calcium ions, decreases their quantity in the blood, and, consequently, in a complex manner in the cell protoplasm. Artificial respiration not only increases the flow of oxygen into an organism but also decreases the lowest temperature threshold of the cold death of an organism. "Conclusions" A decrease in the surviving threshold by $1.5-1.8^{\circ} \mathrm{C}$ is very important from the point of view of reanimation of an organism since to preserve life in the critical period of reanimation each $0.5^{\circ} \mathrm{C}$ are important. Prolongation of minimal frequency of heart contractions and maintaining a minimal arterial blood pressure in an overcooled organism given the body temperature of $11-12.5^{\circ} \mathrm{C}$ is a special problem of great interest associated with many physiological and biological parameters.

Key words: rats, hypothermia, respiration, blood pressure.

\section{Introduction}

When an overcooled man is transported to a clinics or on board a rescue ship, he usually undergoes and intensive rewarming. This often terminates in his death, since the body tissues, especially those of the brain, get warmed rather quickly, hence to preserve their vital ability they require an increased flow of energy. Since respiration is weakened or absent, and the rewarming of the respiration center and heart is delayed, the tissues of an organism cannot obtain sufficient energy supply, and the organism dies. Than the problem arises, which is fundamentally important for medicine: how to stimulate physiological functions of an overcooled organism without rewarming the body?

It is interesting that neither in ancient, medieval, nor in modern medicine there are indications to the methods of resuscitation of a deeply cooled man without rewarming his body, though this problem had been actual both in science and in medical practice for centuries. The death on cold is especially of widespread occurrence during sea catastrophes. The well known in the world insurance company of Lloyd states on the basis of modern statistics that every year thousands of seamen die of cooling in the sea water. Really, when a man with absent respiration, thready pulse, immobile, pale, not reacting to any reflectory stimuli, he is immediately sent to the morgue. The same is being done with a man frozen in a tent in the mountains or covered by a snow avalanche. Though it is known that sometimes a man with the body temperature $18-20^{\circ} \mathrm{C}$ appears to be able to recover independently and to return to life in several hours being in the morgue $[1,2]$.

\section{Is it possible to stimulate respiration and circulation of an overcooled man without rewarming the body}

In 1986 a Canadian physiologist P.Hochachka published a paper [3], where he stated that the disruption of respiration during the development of deep hypothermia is the most important symptom of approaching death of an organism, since respiration never restores spontaneously. Really, a man remaining without help during the arrest of respiration almost inevitably dies. In this paper Hochachka came up with an idea that primary disruptions in the respiration and its complete arrest depend on the accumulation of an excess of $\mathrm{Ca}^{2+}$ in the respiration center cell 
protoplasm. According to a number of indirect data he believed that the accumulation of calcium in the tissues results in a disruption of the processes of energy exchange. Moreover an increase in the $\mathrm{Ca}^{2+}$ content in a cell increases the activity of proteolytic enzymes, which results in the disruption of the membrane structures of a cell. Later Hochachka confirmed his hypothesis [4]. His point of view attracted great interest; however it had no direct experimental confirmations. To obtain the data on the changes in the $\mathrm{Ca}^{2+}$ content in the cells of respiration center the cranium lance is necessary, which in itself has an abrupt impact on respiration. Since there were no direct proofs of Hochachks's point of view, his theory did not gain recognition. We made an attempt to check the validity of this hypothesis by a special method, which will be described further.

The aim of this work was to develop the methods of rescuing the life of overcooled men and to find the lowest temperature threshold of surviving.

\section{Materials and Methods}

\section{Paticipants of the study.}

The experiments were carried out on white male rats with the body mass from 250 to 320 g. Various series of the experiments and (separately) controls consisted of 5-7 animals, which were anaesthetized with urethane (100 $\mathrm{mg}$ per $100 \mathrm{~g})$.

\section{Methods.}

We fixed the head and the body of an animal in a special stand, which was immersed into water with the temperature $7-9^{\circ} \mathrm{C}$. In this case the nostrils and a part of the head remained above the surface. In the case of the experiments with artificial respiration we inserted a short $(3-5 \mathrm{~cm})$ polyethylene tube into the animal trachea. A special miniature apparatus for artificial respiration fed the air into the animal lungs $12-15 \mathrm{ml}$ in volume for the whole animal per minute. The intensity of artificial ventilation of the lungs could be regulated. As the hypothermia developed, we continuously measured the temperature in the rectum with the help of copper-constantan thermocouples. In a series of experiments we also measured the temperature in the esophagus (the heart temperature) and in the brain (the accuracy of the measurements was $0.05^{\circ} \mathrm{C}$ ). We estimated the arterial blood pressure in the femoral artery and also the frequency of the heart contractions and the frequency of respiration. In some experiments we recorded the muscle electrical activity during cold shivering and thermoregulation tone. A preparation of disodium salt of ethylenediaminetetraacetic acid (EDTA) was inserted once or twice. The second insertion followed the first in about 30 minutes.

EDTA reacts with $\mathrm{Ca}^{2+}$ to give a complex compound. The insertion during 4 min of $1 \mathrm{ml}$ of $0.5 \%$ solution of this substance (approximately $0.016 \mathrm{mmol}$ ) decreased the content of $\mathrm{Ca}^{2+}$ in the blood of various white rats by $15-25 \%$. Such a dose did not produce any accessory effects. Between the normal content of $\mathrm{Ca}^{2+}$ in a nervous cell $\left(10^{-7}-10^{-8} \mathrm{M}\right)$ and its content in the intercellular liquid $\left(10^{-4} \mathrm{M}\right)$ there is a great gradient of calcium ion concentration. Such a concentration gradient requires great energy expenses for evacuation of the excess of calcium ions from the cell to the intercellular medium. An energy deficit for pumping out calcium ions from cooled tissues results in an accumulation of these ions in the cell and disrupts its work. We believed that a decrease in the $\mathrm{Ca}^{2+}$ content in the blood must decrease the $\mathrm{Ca}^{2+}$ content in the intercellular liquid and decrease the gradient of $\mathrm{Ca}^{2+}$ concentrations between intercellular medium and the cell protoplasm. This in its turn must decreases energy expenditures for pumping out the excess of $\mathrm{Ca}^{2+}$ from the cell, normalize the content of $\mathrm{Ca}^{2+}$ in the cell, and stimulate its work even at a very low environmental temperature.

\section{Results}


At the beginning of our studies we used the above described method of resuscitating a cooled organism without rewarming during relatively mild hypothermia, when the temperature in the medulla oblongata was $21-22^{\circ} \mathrm{C}$. At such a temperature the reaction of increasing the heat production as cold shivering and thermoregulation tone almost disappeared in animals. However after insertion of $1 \mathrm{ml}$ of $0.5 \%$ solution of EDTA in 10-12 minutes we were able to trigger the fits of cold shivering given the temperature of the medulla oblongata about $20^{\circ} \mathrm{C}$, and after repeated injection of EDTA the level of the muscle electrical activity increased to $60-80 \%$ of the norm in 10-12 minutes at the same body temperature of the animal. After injection of EDTA the frequency of the respiration movements increased from $44 \pm 2$ to $57 \pm 4 \%$ per minute, and after repeated injection it increased to $70 \%$ of the norm $[5,6]$. If we ceased to cool the animals and decrease their body temperature and left them in a warm room with the temperature $22-24^{\circ} \mathrm{C}$, in several hours the animals warmed up on their own with the help of restored cold muscle shivering and returned to normal life.

However the most surprising in the action of EDTA on a living organism is the stimulation of the skin cold thermo receptors. These experiments were carried out on the skin of a rabbit nose back. Their result is given in Table 1.

Table 1. Disappearance of thermoreceptor impulsation during excessive cooling of the skin and its restoration after insertion of EDTA

\begin{tabular}{|l|l|l|l|l|}
\hline \multicolumn{1}{|c|}{ Receptor number } & $\begin{array}{c}\text { Skin temperature at } \\
\text { the site of receptor } \\
\text { location, }{ }^{\circ} \mathrm{C}\end{array}$ & $\begin{array}{c}\text { before EDTA } \\
\text { insertion, } \mathrm{s}^{-1}\end{array}$ & $\begin{array}{c}\text { Maximal impulsation } \\
\text { frequency after EDTA } \\
\text { insertion, } \mathrm{s}^{-1}\end{array}$ & $\begin{array}{c}\text { The time of attaining } \\
\text { maximal impulsation } \\
\text { frequency after EDTA } \\
\text { insertion, min }\end{array}$ \\
\hline 1 & 5 & 0 & 18 & 5 \\
\hline 2 & 3,1 & 3 & 18 & 2 \\
\hline 3 & 0 & 0 & 16 & 8,5 \\
\hline 4 & 4,8 & 0 & 20 & 3 \\
\hline 5 & 0 & 3 & 11 & 3,5 \\
\hline $\begin{array}{l}\text { Mean value } \pm \text { standard } \\
\text { deviation * }\end{array}$ & $2,6 \pm 3$ & $1 \pm 1$ & $17 \pm 2$ & $4,6 \pm 0,3$ \\
\hline
\end{tabular}

Note *Here and in Tables 2-5.

From Table 1 the stimulating influence of EDTA on the impulsation of cold thermoreceptors becomes obvious. Sufficiently abrupt cooling of the skin results in oppression of thermoreceptor impulsation from 0 to 3 per second. Insertion of EDTA releases this oppression of impulsation. According to our data at the temperature of impulsation paralysis the cold receptor impulsation achieved 18-20 impulses per second. Therefore EDTA can directly excite thermoregulation reactions. An intensified impulsation of cold receptors may also excite the respiration and heart activity.

The results of all the studies given above were described in our review [5], papers and monographs [6-12]. We obviously demonstrated a favorable action of disodium salt of EDTA on a cooled organism. It is important to note that this substance is present in Pharmacopeia and is used in medicine to prevent pathological lime loss of the tissues. In Pharmacopeia there are instructions about the methods of inserting this substance into an organism and the data about the safe doses. Therefore we can even now suggest to various rescue services this preparation, which is the product of our studies and experimentally proved to be the substance for resuscitation of overcooled organism as a remedy from overcooling.

The first method of restoration of vital activity of an organism without rewarming during deep hypothermia with the arrest of respiration.

New problems arose as our work developed. It was necessary to test the advanced method of fighting against overcooling after cold arrest of respiration, which is a symptom of actual death of a cooled animal. In this context hereafter we studied the possibility of resuscitation of a 
cooled organism after more or less prolonged time laps after the arrest of respiration. The second problem resulting from the first is to find the lowest temperature threshold of animal life.

We tried to solve these problems with the help of gradual cooling of animals to a complete respiration arrest. Further in about 10-15 minutes after respiration arrest we inserted a certain dose of EDTA into the animal blood. Then we thoroughly observed the restoration of respiration and other physiological parameters. We obtained various data for various animals, hence we give them in the Tables, where this dispersion could be seen and estimated (Tables 2$3)$.

Table. 2 Physiological parameters of the rats in 15 minutes after the arrest of respiration

\begin{tabular}{|l|l|l|l|l|}
\hline $\begin{array}{c}\text { Temperature in the } \\
\text { rectum, }{ }^{\circ} \mathrm{C}\end{array}$ & $\begin{array}{c}\text { Brain } \\
\text { temperature, }{ }^{\circ} \mathrm{C}\end{array}$ & $\begin{array}{c}\text { Arterial blood } \\
\text { pressure, mm Hg }\end{array}$ & $\begin{array}{c}\text { Frequency of } \\
\text { respiration, } \\
\text { cycles/min }\end{array}$ & $\begin{array}{c}\text { Frequency of } \\
\text { heart } \\
\text { contractions, } \\
\text { beat/min }\end{array}$ \\
\hline 13,5 & 13,9 & 20 & 0 & 25 \\
\hline 11,4 & 13,4 & 10 & 0 & 10 \\
\hline 12,8 & 14,0 & 18 & 0 & 25 \\
\hline 14,0 & 15,0 & 10 & 0 & 10 \\
\hline 13,2 & 15,7 & 18 & 0 & 20 \\
\hline 14,3 & 16,1 & 10 & 0 & 19 \\
\hline 14,8 & 15,8 & 24 & 0 & 16 \\
\hline $\mathbf{1 3 , 4 \pm 0 , 6}$ & $\mathbf{1 4 , 8 \pm 0 , 2}$ & $\mathbf{1 6} \pm \mathbf{6 , 1}$ & $\mathbf{0}$ & $\mathbf{2 1} \pm \mathbf{5 , 0}$ \\
\hline
\end{tabular}

Table 3. Physiological parameters of the same animals in 15 minutes after the arrest of respiration and immediate insertion of $1 \mathrm{ml}$ of $0.5 \%$ solution of EDTA

\begin{tabular}{|l|l|l|l|l|}
\hline $\begin{array}{c}\text { Temperature in } \\
\text { the rectum, }{ }^{\circ} \mathrm{C}\end{array}$ & $\begin{array}{c}\text { Brain } \\
\text { temperature, }{ }^{\circ} \mathrm{C}\end{array}$ & $\begin{array}{c}\text { Arterial blood } \\
\text { pressure, } \mathrm{mm} \mathrm{Hg}\end{array}$ & $\begin{array}{c}\text { Frequency of } \\
\text { respiration, } \\
\text { cycles/min }\end{array}$ & $\begin{array}{c}\text { Frequency of } \\
\text { heart } \\
\text { contractions, } \\
\text { beat/min }\end{array}$ \\
\hline 11,6 & 13,8 & 36 & 6 & 41 \\
\hline 12,3 & 13,8 & 48 & 8 & 84 \\
\hline 13,2 & 15,6 & 66 & 24 & 63 \\
\hline 14,1 & 15,6 & 50 & 18 & 66 \\
\hline 9,5 & 14,9 & 24 & 6 & 36 \\
\hline 12.7 & 15.4 & 36 & 12 & 52 \\
\hline $\mathbf{1 2 , 2 \pm 0 , 7}$ & $\mathbf{1 4 , 9 \pm 0 , 3}$ & $\mathbf{4 3}+\mathbf{6}$ & $\mathbf{1 2 \pm 3}$ & $\mathbf{5 7 \pm 7}$ \\
\hline
\end{tabular}

Judging from the data of Table 2, as the temperature in the rectum attained $13.4^{\circ} \mathrm{C}$ and in the brain -14.8 , the respiration in the animals was arrested. After the arrest of respiration in the animals a low frequency of the heart contractions and a minimal blood pressure were preserved. If immediately after the arrest of respiration EDTA was inserted into the animal blood, in 60 minutes after insertion they demonstrated the restoration of a certain volume of external respiration. Their arterial blood pressure and the frequency of the heart contractions distinctly increase (see Table 3). The arterial blood pressure increased from 16 to $43 \mathrm{~mm} \mathrm{Hg}$, the frequency of the heart contractions - from 21 to 57 per minute. These data point to the fact that injection of EDTA can restore the life of an organism, which is practically near to death owing to the absence of respiration, which, as is well known to resuscitation physicians, never restores spontaneously during hypothermia.

After ceasing cooling at the temperature in the room $22-24^{\circ} \mathrm{C}$ the animals rewarmed on their own and returned to life in several hours. 
The second method of restoration of vital activity of an organism after deep hypothermia without rewarming

At the beginning of this year our colleague N.K.Arokina made experiments on revealing the influence of artificial respiration on the vital activity of deeply cooled animals, when they lost the function of external respiration. Table 4 shows that the animals, which were in water with the temperature $8-9^{\circ} \mathrm{C}$ and had the average rectum temperature $15.4^{\circ} \mathrm{C}$ and in the brain $17.9^{\circ} \mathrm{C}$, completely lost their respiration. The frequency of the heart contractions was in the average $21.3 \mathrm{beat} / \mathrm{min}$, and the level of arterial blood flow $-20.4 \mathrm{~mm} \mathrm{Hg}$.

Table 4. Arrest of respiration and an abrupt decrease in the arterial blood pressure and frequency of the heart contractions after staying in water with the temperature $8-9^{\circ} \mathrm{C}$

\begin{tabular}{|l|l|l|l|l|l|}
\hline $\begin{array}{c}\text { Temperature in the } \\
\text { rectum, }{ }^{\circ} \mathrm{C}\end{array}$ & $\begin{array}{l}\text { Temperature in the } \\
\text { esophagus, }{ }^{\circ} \mathrm{C}\end{array}$ & $\begin{array}{c}\text { Brain temperature, } \\
{ }^{\circ} \mathrm{C}\end{array}$ & $\begin{array}{c}\text { Frequency of } \\
\text { respiration, } \\
\text { cycles/min }\end{array}$ & $\begin{array}{c}\text { Frequency of heart } \\
\text { contractions, } \\
\text { beat/min }\end{array}$ & $\begin{array}{c}\text { Arterial blood } \\
\text { pressure, mm Hg }\end{array}$ \\
\hline 15 & 16 & 17,6 & 0 & 17 & 25 \\
\hline 17,2 & 18,4 & 19,7 & 0 & 21 & 20 \\
\hline 14 & 15 & 16,3 & 0 & 17 & 30 \\
\hline 14,5 & 16,6 & 0 & 23 & 10 \\
\hline 15,5 & 18,7 & 0 & 24 & 24 \\
\hline 14,5 & 17,4 & 0 & 28 & 18 \\
\hline 17 & 15,8 & 17,1 & 0 & 19 & 14 \\
\hline $\mathbf{1 5 , 4 \pm 0 , 5}$ & 18,4 & 19,3 & $\mathbf{0}$ & $\mathbf{2 1 , 3} \pm \mathbf{1 , 5}$ & $\mathbf{2 0 , 4 \pm 2 , 6}$ \\
\hline
\end{tabular}

Table 5. Experimental rats. 2 minutes after the beginning of artificial respiration. 12-13 inhales per minute.

\begin{tabular}{|l|l|l|l|l|l|}
\hline $\begin{array}{c}\text { Temperature in the } \\
\text { rectum, }{ }^{\circ} \mathrm{C}\end{array}$ & $\begin{array}{c}\text { Temperature in the } \\
\text { esophagus, }{ }^{\circ} \mathrm{C}\end{array}$ & $\begin{array}{c}\text { Brain temperature, } \\
{ }^{\circ} \mathrm{C}\end{array}$ & $\begin{array}{c}\text { Frequency of } \\
\text { respiration, } \\
\text { cycles/min }\end{array}$ & $\begin{array}{c}\text { Frequency of heart } \\
\text { contractions, } \\
\text { beat/min }\end{array}$ & $\begin{array}{c}\text { Arterial blood } \\
\text { pressure, } \mathrm{mm} \text { Hg }\end{array}$ \\
\hline 13,7 & 14,9 & 16,4 & 13 & 58 & 40 \\
\hline 14 & 15,2 & 17 & 13 & 45 & 30 \\
\hline 13 & 14,4 & 15,6 & 12 & 55 & 46 \\
\hline 13,9 & 15,8 & 12 & 58 & 28 \\
\hline 13,9 & 15,9 & 17,6 & 12 & 72 & 42 \\
\hline 12,5 & 14,4 & 15,6 & 12 & 44 & 36 \\
\hline 14,5 & 15,6 & 17,0 & 12 & 70 & 40 \\
\hline $\mathbf{1 3 , 6 \pm 0 , 2}$ & $\mathbf{1 5} \pm \mathbf{0 , 2}$ & $\mathbf{1 6 , 4} \pm \mathbf{0 , 3}$ & $\mathbf{1 2 , 3} \pm \mathbf{0 , 2}$ & $\mathbf{5 7 , 4} \mathbf{4}, \mathbf{1}$ & $\mathbf{3 7 , 4} \pm \mathbf{2 , 5}$ \\
\hline
\end{tabular}

After the arrest of respiration the animals received artificial respiration (12-13 inhales 1 $\mathrm{ml}$ of air each). It is fascinating that in the previous experiments at the temperatures in the rectum and brain, which meant the arrest of respiration and death, in 2 minutes of artificial respiration almost at the same or even lower temperature the frequency of the heart contractions in an organism increased by $37 \mathrm{beat} / \mathrm{min}$ and the arterial pressure - by $17 \mathrm{~mm} \mathrm{Hg}$. We emphasize that these increases in the arterial pressure and frequency of the heart contractions occurred at the rectum temperature lower by $1.8^{\circ} \mathrm{C}$ and in the brain by $1.5^{\circ} \mathrm{C}$ than in the control group (Tables 4 and 5). For the animals that were in such a distressing state (actually at the threshold of death) these are substantial changes. Unfortunately our apparatus for artificial respiration could not provide more than 13 inhales per minute. A rat has lung ventilation of about $70-90 \mathrm{ml}$ of air per minute. We could provide only $12-13 \mathrm{ml}$ per minute. When the body temperature is $14-16^{\circ} \mathrm{C}$, oxygen consumption by a rat decreases by factors 5-7. This decreases the demand for oxygen. Nevertheless the volume of ventilation we could provide was evidently insufficient, since during further stay in water with the temperature $8-9^{\circ} \mathrm{C}$ the animals continued to reduce the temperature rapidly. However they preserved the minimal level of arterial pressure and the frequency of the heart contractions up to the temperature $11^{\circ} \mathrm{C}$ in the rectum and $12.5^{\circ} \mathrm{C}$ in the brain. Bearing in mind a complete loss of vital ability the artificial respiration can decrease the temperature 
threshold of surviving at least by $2-3^{\circ} \mathrm{C}$. From the point of view of reanimation of an overcooled organism this is a substantial physiological shift.

\section{Discussion}

We emphasize that from the époque of ancient medicine and almost up to nowadays rewarming was the only method of rescuing an overcooled organism from death. No other methods of resuscitation an organism after deep hypothermia existed in medicine up to now. This method is extremely dangerous especially upon rigorous rewarming. It often results in the death of an overcooled man. From thousands of seamen, who died of cold, many hundredths died owing the wrong method of their rescuing. Upon deep cooling at the beginning of rescue operation it is necessary to stimulate respiration and heart activity by EDTA injection. It is impermissible to warm an organism intensively before the respiration, even though weak but spontaneous, is restored. Then the victim of overcooling must be left in a warm room and covered with a warm cover. There are many chances that the respiration gradually achieves the norm, the cold shivering as a source of the heat production becomes restored and a man will return to life.

The other method of restoring the vital activity of a deeply cooled organism without rewarming the body is artificial respiration. It is usually applied when the respiration weakens abruptly. If the respiration is arrested, artificial respiration is not commonly used. However we were able to show that artificial respiration not only restores oxygen supply of an organism upon a complete arrest of respiration. By our data artificial respiration also decreases the lowest temperature threshold of life by several degrees, which is of greatest significance in the reanimation of an overcooled man. Therefore, artificial respiration allows the heart to beat and maintain a minimal arterial pressure at the temperatures, which are completely deadly for the test animals without artificial respiration. When a man who lost respiration from cold and is unable to react to reflex stimulations is lifted on board the rescue ship, or when such a victim of overcooling during mountain explorations or expeditions gets into the hands of mountain rescuers, or when a man is covered by snow avalanche, the first thing the rescuer does - he starts to warm the victim. Whereas first of all it is necessary, even given a thready pulse, to apply artificial respiration, for example "mouth to mouth". An important assumption may be made on the basis of our experiments with artificial respiration. According to Tables 4 and 5 the animals restore their functions and survive at minimal arterial pressure (in some experiments at the pressure of only 10-14 $\mathrm{mm} \mathrm{Hg}$ ). In essence such a pressure cannot provide for the vital activity of an organism. Nevertheless given such pressure the artificial respiration increased the arterial pressure by 18-26 mm Hg, and the animals survived. An assumption arises that periodical filling of the lungs with air stimulates the functions of the cardiovascular system at its almost complete arrest upon cooling. If it is so, we can expect that upon intensive artificial respiration spontaneous heart contractions can be initiated and a minimal level of arterial pressure may be maintained at a very low body temperature of an animal and, possibly, of a man.

\section{Conclusions}

All the data presented allow an unexpected conclusion to be made about the fact that an organism in the state of deep hypothermia does not die directly from cold. It dies from the deficit of oxygen or, more adequately said, of energy. This allows us to reconsider fundamentally the rescue operations for prevention of the death of an overcooled organism. We emphasize that Schmidt-Nielsen, who is a generally recognized specialist in the field of evolution physiology and morphology, made out the fact that the physiological mechanisms of respiration are completely identical in all the classes of mammals. He considers being identical also biophysical properties of respiration organs in them. So, for example, the spring of lung tissues in elephant 
and mouse are practically the same [13]. Just for this reason all the procedures of resuscitation of respiration in rats after deep hypothermia are quite acceptable also for humans.

\section{REFERENCES}

1. Barton A., Edholm O. Man in a cold environment. B. Saunders Company, London, 1955. 333 p.

2. Harnett R.M, Pruitt J.R., Sias F.R. A review of the literature concerning resuscitation from hypothermia. Aviat. Space Environ. Med. 1983; 54: 487-495.

3. Hochachka P.W., SomeroG.N. Strategies of biochemical adaptation. W.B.Saunders Company, London, 1973.

4. Hochachka P.W., Somero G.N. Biochemical adaptation. Mechanism and process in physiological evolution. Oxford University Press, 2002. 466 p.

5. Ivanov K.P. Physiological blocking of the mechanisms of cold death. J. Therm. Biol. 2000; 25: 467-479.

6. Ivanov K.P. Osnovy energetiki organizma. T. 3 [Fundamentals of Human Energy. Volume 3].

Nauka, St. Peteresburg, 2001. 275 p.

7. Ivanov K.P. Osnovy energetiki organizma. T. 4 [Fundamentals of Human Energy. Volume 4].

Nauka, St. Peteresburg, 2004. 250 p.

8. Fedorov G.S., Potekhina I.L. Ros. fiziol. zhurn. im. I.M. Sechenova - I.M. Sechenov

Russian physiological journal. 2005; 91 (10): 1205-1212.

9. Fedorov G.S., Arokina N.K. . Ros. fiziol. zhurn. im. I.M. Sechenova - I.M. Sechenov

Russian physiological journal. 2006; 92 (11): 1373-1381.

10. Ivanov K.P. Uspekhi fiziol. nauk - Achievements of physiological sciences. 2007; 38 (2):

$63-74$.

11. Ivanov K.P. Restoration of vital activity of cooled animals without rewarming the body. Eur. J.Appl. Physiol. 2009; 105: 5-12.

12. Arokina N.K., Fedorov G.S. Pat. fiziol. i eksp. ter. - Journal of pathophysiology and experimental therapy. 2011; 4: 55-58.

13. Schmidt-Nielsen K. Why is animal size so important? Cambridge University press, Cambridge, London, New York, 1984. 280 p.

\section{FOR CORRESPONDENCE}

Ivanov Kirill Pavlovich, $\mathrm{PhD}$, professor, head of the laboratory of thermoregulation and bioenergetics of I.P.Pavlov Institute of Physiology, honored scientist of Russian Federation

Address: 6, Nab. Makarova, St.Petersburg, Russia. 199034, tel.: +7 (812) 293-76-80,

e-mail: kpivanov@nc2490.spb.edu 